\title{
EL NACIMIENTO DE LA DOMESTICIDAD BURGUESA EN EL ANTIGUO RÉGIMEN. NOTAS PARA SU ESTUDIO
}

\author{
GLORIA A. FRANCO RUBIO \\ Universidad Complutense
}

Fecha de recepción: enero 2012

Fecha de aceptación: febrero 2012

En el curso de una investigación más amplia que vengo desarrollando desde hace unos años sobre distintos aspectos de la vida cotidiana en la España moderna ${ }^{1}$, uno de los temas que más ha atraído mi atención -y que necesita con urgencia ser tratado como merece- ha sido el de la domesticidad. Ese interés me ha conducido a plantear algunos interrogantes que pueden contribuir a descubrir cómo, a lo largo de ese periodo tan largo de tiempo que denominamos Edad Moderna o Antiguo Régimen, pudo ir emergiendo una forma novedosa de entender la vida en el entorno doméstico que acabaría imponiéndose a nivel generalizado; ponderar hasta qué punto fue innovadora esa nueva domesticidad para encontrar otros ejes fundamentales sobre los que apoyarse, desestimando los que le venían sirviendo hasta ahora. Un hecho que iba a traer consigo importantes consecuencias en el terreno personal y en el orden social, tal como estaba constituido hasta la fecha. Esa nueva interpretación de la domesticidad estuvo acompañada de unos discursos y de unas prácticas que van a contribuir a la delimitación del espacio social en dos esferas, la relacionada con lo doméstico y lo privado y la relacionada con lo público. Así pues, domesticidad, privacidad y publicidad discurrirán en el tiempo de forma paralela aunque no alcanzarán una conformación más definida hasta finales del Antiguo Régimen. Son tres procesos distintos, cada uno con sus características propias, que operaron simultáneamente en el tiempo hasta alcanzar su identidad

\footnotetext{
1. Este trabajo se inscribe en el marco del Proyecto de Investigación HAR2011-26435-C03-01 titulado «El hecho cotidiano en la Monarquía Española de la Edad Moderna: lo doméstico, entre lo privado y lo público»; con el subtítulo «Historia comparada entre el interior y la periferia» se halla coordinado entre las universidades de Barcelona, Granada y Complutense de Madrid.
} 
definitiva; una identidad forjada en la dicotomía que se iba a establecer entre lo privado/lo público y/o lo doméstico/lo público.

Debo empezar diciendo que se trata de un trabajo que se encuentra aún en fase de elaboración, a pesar de que engloba resultados parciales de la investigación en curso a la que acabo de referirme. No obstante, precisa todavía de la consulta de un mayor número de fuentes y de bibliografía especializada antes de poder avanzar resultados concluyentes. Por tanto, mi intención en estas páginas sería, más bien, la de compartir con potenciales lectores de este Monográfico una serie de reflexiones, de comentarios, y de sugerencias que puedan servir para acometer el estudio de la domesticidad y del proceso de delimitación de lo doméstico en la sociedad del Antiguo Régimen. Se trataría de rastrear tanto la génesis como la evolución y el desarrollo de un concepto y una actitud -unos discursos y unas prácticas, desde la óptica de la Historia cultural- que iba a provocar importantes consecuencias a nivel cotidiano hasta desembocar en la construcción de una domesticidad distinta a la existente, cada vez más en consonancia con la ideología de la burguesía, cuyos resultados van a ser fundamentales para la construcción del orden burgués, cuando triunfe plenamente en la sociedad liberal.

Supone un ambicioso plan de trabajo que intenta abordar y captar de una forma poliédrica, los diferentes registros y ángulos del proceso de reinvención de un concepto que ya existía previamente aunque no estuviera formalmente conceptualizado; un ejercicio del que ahora se ocuparán los moralistas, secundados por los teóricos de la política. Estudiar el ámbito doméstico nos coloca en una dimensión analítica, en un campo de observación y en una escala de análisis que se sitúa en el punto de intersección de un marco histórico más amplio donde se cruzan, principalmente, dos líneas de investigación, la Historia de la vida cotidiana y la Historia de las mujeres; dos corrientes historiográficas que se han ido diversificando, enriqueciendo y renovando paulatinamente en los últimos años, a las que habría que entrecruzar con disciplinas afines como la Historia de la Familia y la Historia de la Cultura material, sin olvidar las aportaciones de la Antropología, de la Economía, la Sociología, la Historia del Arte y la Psicología Social. Desde un punto de vista interdisciplinar, supone todo un cúmulo de desafíos de tipo teórico, metodológico y heurístico que pueden hacer aún más atractivo, si cabe, su estudio.

A comienzos de la Edad Moderna no existía una definición clara de los diversos espacios, ni reales ni simbólicos, que componían la sociedad. El abigarrado orden feudal se había ido forjando a base de la superposición y connivencia de poderes, estamentos y jurisdicciones con sus respectivas redes de parentesco, señoriales, clientelares, de patronazgo y hasta de mecenazgo, haciendo que, en la práctica, se diera una gran confusión entre todos ellos y las diferentes realidades en que operaban. De este modo se originaban múltiples interferencias entre las diversas instancias, haciendo que los espacios simbólicos de representación estuvieran mezclados, sin poder establecerse una distinción entre aquello que era propio del ámbito público y aquello reservado al ámbito privado o doméstico, una confusión a la que se añadía el que muchas actividades que deberían haber sido privadas se realizaran en público o que, de la misma manera, determinados actos de carácter manifiestamente público se realizaran en un 
entorno privado. No era fácil marcar el límite entre ambas, ni deslindar la naturaleza pública o doméstica de numerosas actividades cotidianas como, por ejemplo, la elaboración de una pieza manufacturada; realizada en colaboración con otras personas del mismo oficio, y destinada a la venta podía hacerse no en un lugar específico como un taller, sino en el interior de una vivienda simultaneándola con otras faenas domésticas y caseras realizadas en la tranquilidad del hogar. Y, sin embargo, eso era lo corriente y lo habitual, como podemos inferir al observar esas representaciones visuales de casastaller que nos han dejado las fuentes iconográficas de la época o las descripciones literarias de la realidad cotidiana.

\section{LA DOMESTICIDAD COMO CONCEPTO Y SU EVOLUCIÓN}

Según la etimología de la palabra doméstico, en la lengua griega la palabra domos servía para describir la vivienda y sus interiores, mientras que en la latina el término domus hacía referencia al linaje, a la casa en sentido familiar y de parentesco ${ }^{2}$. En griego cuando se quería aludir a la familia como célula básica de la sociedad se utilizaba la voz oikos, independientemente de que ésta pudiera ser entendida en una acepción más amplia con una triple significación. Por un lado servía para designar el espacio físico, la vivienda, el lugar donde habitaba la familia como unidad social más básica; de otra, a los miembros que la conformaban y, por último, hace referencia a los bienes materiales y propiedades de todo tipo (esclavos, animales) de que ésa disponía. De hecho, la tercera significación es la que utilizan preferentemente los antropólogos cuando quieren referirse a la producción doméstica ${ }^{3}$.

Presente en las culturas del occidente europeo desde la época clásica, supo dotarse de la capacidad necesaria para adaptarse a las diversas circunstancias espacio-temporales, a los diferentes contextos históricos, e ir evolucionando internamente hasta poder perpetuarse a través de la tradición heredada.

El Tesoro de la Lengua Castellana o Española de Sebastián de Covarrubias, publicado en 1611, define la palabra doméstico de la siguiente manera: «todo lo que se cría en casa y por esta razón es manso y apacible más de lo que se cría en el campo; y no sólo al animal llamamos doméstico más aún al que está obediente al padre o al señor». Es decir, que en la acepción que la sociedad española de la época entendía por doméstico está implícita la idea de obediencia y subordinación, tanto refiriéndose a la que tienen las personas hacia una autoridad superior como a una conducta determinada de los animales hacia los humanos, que igualmente entraña subordinación. Al mismo tiempo, en un sentido subyacente, hay una cierta relación entre lo que afecta a un orden

2. La casa campesina, unidad de residencia y unidad económica de producción es la domus de la que habla extensamente Le Roy Ladurie en su estudio sobre Montaillou. Vid. LE Roy LADURIE, Emmanuel: Montaillou, aldea occitana de 1294 a 1324. Madrid. Taurus, 1981.

3. El término de oikos fue introducido por K. RODBERTUS en 1865 para hacer alusión a los grandes dominios familiares romanos que contaban con una gran mano de obra esclava, lo que les permitía actuar como una verdadera empresa económica. 
regulado y amable (el que concierne al interior) y una ausencia de orden, o des-orden, que puede llegar a ser hostil, y que se corresponde con el exterior.

El Diccionario de Autoridades (1727) describe el adjetivo doméstico de la siguiente forma: «en su riguroso sentido vale todo lo que pertenece o es propio de la casa. Es del latín domesticus que significa lo mismo». Por su parte, el verbo domesticar es definido como «ablandar, reducir, hacer tratable y dócil al animal indómito y feroz y tal vez se suele decir del hombre. Viene del nombre latino domus que significa «la casa». Asimismo indica que el adverbio domésticamente es sinónimo de caseramente y familiarmente» ${ }^{4}$. Como podemos observar, el espíritu que impregna los diferentes vocablos mantiene la misma idea que el anterior, relacionando estrechamente la domesticidad con el amaestramiento, de personas o de animales, lo cual es muy significativo porque está implícita la alusión al acatamiento, obediencia y sumisión a un orden regulado previamente.

En la actualidad, el Diccionario de la Real Academia Española define la domesticidad como «calidad o condición de doméstico»; de nuevo el verbo domesticar tiene la doble acepción referida a los animales, y a los seres humanos. En relación a los primeros se define como «reducir, acostumbrar a la vista y compañía del hombre al animal fiero y salvaje», y respecto a los segundos como «hacer tratable a una persona que no lo es, moderar la aspereza de carácter». En cuanto al adjetivo doméstico, siguen prevaleciendo varios significados, primero como «perteneciente o relativo a la casa $\mathrm{u}$ hogar, segundo «aplícase al animal que se cría en la compañía del hombre, a diferencia del que se cría salvaje», y tercero «dícese del criado que sirve en una casa» ${ }^{5}$, siendo sus sinónimos por un lado los términos manso, dócil y sumiso y, por otro, casero, hogareño y familiar. Como podemos observar hay una idea de continuidad léxica y filológica que mantiene la misma significación que en el pasado. En cuanto a la palabra casa, es presentada bajo la forma de distintos registros, en los que siempre subsisten dos: por un lado, el que remite al marco espacial, incluye todo lo relativo al domicilio, hogar, vivienda, morada, residencia y habitación. Por otro, a la familia como grupo de parentesco y, por lo tanto, al linaje, la raza, la estirpe, la sangre, la prosapia etc $^{6}$.

Este conjunto de términos lingüísticos a que acabamos de aludir adopta formas verbales, adjetivales y adverbiales en los diversos idiomas europeos guardando una estrecha similitud y concomitancias entre ellos. Tomando como base el latín y como referencia otras lenguas modernas, todas ellas resultarán muy útiles para adentrarnos en el tema que nos ocupa. La domus latina, contemplada en la triple acepción que hemos comentado tiene su correspondencia, por un lado, en la casa de española ${ }^{7}$, la famille francesa y la family inglesa; por otro, con el hogar español, el accueil francés y la home inglesa y, finalmente, con la vivienda española, la maison francesa y la house

\footnotetext{
4. Diccionario de Autoridades. Madrid. Editorial Gredos, 1963. Edición facsímil. Volumen D-Ñ, p. 331.

5. Diccionario de la Lengua Española. Madrid. Real Academia Española, 1992. Tomo a-g, pp. 772-773.

6. Ibidem, pp. 428-429.

7. La Casa de Alba, la Casa de Osuna y otras nobiliarias son un buen ejemplo de ello.
} 
inglesa. Mientras que el adjetivo latino domesticus aparece denominado como doméstico en español, menage en francés y household en inglés.

La domesticidad es una invención, es decir, una construcción cultural; un concepto abstracto que hace referencia a la forma de concebir el hogar y el espacio circunscrito a él de manera que la ocupación física, psicológica y simbólica de la vivienda adquiere unos rasgos determinados, llegando a generar un estilo y una forma determinada de vida; en este sentido, presupone la intencionalidad y la voluntad de crear en el interior de los hogares un clima considerado ideal por los propios moradores; un marco para la convivencia y cohabitación que, al basarse en ciertas reglas que facilitan la satisfacción de las necesidades fisiológicas y emocionales, puede asegurar el orden y la estabilidad internas, siendo percibido por sus residentes como radicalmente distinto al espacio exterior, en tanto que desordenado e inestable. Algunos autores como Edward Shorter hacen una interpretación más restrictiva de la domesticidad; para el historiador de la familia inglés la domesticidad está ligada a la familia moderna, la familia nuclear, y es definida como «la conciencia que tiene la familia de sí misma como una preciosa unidad emocional que debe ser protegida de los extraños con privacidad y aislamiento ${ }^{8}$.

En el aspecto material supone desplegar una serie de objetos que posibiliten el día a día de la vida más agradable en todos los sentidos, lo que nos llevaría a hablar de la comodidad o de la confortabilidad en términos psicológicos; es decir, en cómo la disposición de los espacios, del mobiliario, de la decoración y de todos los objetos que forman parte de ella se disponen y reparten en función de los sentidos, de los sentimientos, de las emociones y de la afectividad. En el aspecto psicológico, la domesticidad entraña lograr una cierta atmósfera de bienestar, de calidez y de agrado que mantenga un clima interior lo suficientemente cómodo y gratificante a sus habitantes que les resulte casi edénico; un ambiente, en suma, lo convenientemente atractivo y deseable como para resultar placentero hasta el punto de surgir la creencia de que en él se podría hallar la felicidad terrena. Frente a los consejos dictados por los manuales de conducta, cuyo florecimiento iría in crescendo a lo largo del Antiguo Régimen, de mantener en público el autodominio de las emociones y de los sentimientos, lo doméstico permite dar rienda suelta a las emociones, porque la relajación y la expresión libre de los sentidos y de los sentimientos está permitida y estimulada. Para describir ese ambiente Mario Praz escoge el término alemán de stinmung que significa ambiente, atmósfera y se refiere a ella con las siguientes palabras: «la sensación conjunta de intimidad que crean una habitación y sus elementos. Se trata de una cualidad de los interiores que no tiene tanto que ver con su funcionalidad como con la forma en que la habitación refleja el carácter y el alma del propietario, prevalente a la del usuario femenino», afirmando de paso que este concepto nació en el norte de Europa'.

8. SHORTER, Edward: El nacimiento de la familia moderna. Buenos Aires. Crea, 1972, p. 265.

9. PrAZ, Mario: An Illustrated History of Interior Decoration: from Pompei to Art Nouveau. New York. Thames and Hudson, 1982. Citado por EsPegel, Carmen: Heroínas del espacio. Buenos Aires. Nobuko, 2007, p. 30 . 
En el aspecto social se considera doméstica aquella parte de la sociabilidad humana que se desarrolla a espaldas de lo que hemos dado en llamar esfera pública. Mientras ésta abarca el conjunto de todas las relaciones que pueden darse entre los individuos respecto de la comunidad, de las instituciones, de las asociaciones, del estado y con el resto de la sociedad, todo lo que no forme parte de ese juego entraría en la sociabilidad propia de la vida doméstica, marcada por las relaciones directas, más interpersonales y, a veces, identificada con la privacidad.

A nivel normativo la domesticidad cumplirá un papel bien definido en la regulación del orden social, amaestrando a los individuos para atemperar, contener y templar sus instintos, codificar sus comportamientos, y moderar sus sentimientos para que puedan someterse y acatar el orden social. Que la domesticidad actuara como órgano regulador no impidió que ella misma fuera también sometida a un proceso de autoreglamentación. Cabe pensar que la formulación del espacio doméstico responde igualmente a unas estrategias determinadas que le harían jugar un papel determinante en la fabricación del espacio social. Así como el ámbito público tiene sus propios canales de instrucción y formación, el doméstico también dispondría de los suyos; a su sombra se forja la modelación de las conductas del ser humano desde que nace hasta el momento de su socialización (escuela) así como su preparación inicial en los aprendizajes de la vida para llegar a ser un buen ciudadano. A largo plazo, esta domesticación de los individuos en el ámbito familiar - la familia entendida como microcosmos social-, era una premisa necesaria para el buen funcionamiento macrosocial, y se designaría a los padres como los agentes encargados de llevarla a cabo. En el nuevo orden liberal el padre, depositario de la autoridad familiar se encargará de tener lo necesario para mantener a flote a la familia y proporcionar una buena educación a sus hijos, la «nueva» madre, además de su crianza y cuidado, tendrá una cierta corresponsabilidad en la tarea formativa de los hijos. Llegados a este punto, la madre reproductora y nutricia sería sustituida por la madre educadora, capaz de formar buenos ciudadanos para la nueva sociedad.

\section{PLANTEAMIENTOS CONCEPTUALES Y METODOLÓGICOS}

Como decía anteriormente, una de las premisas básicas sería partir de la consideración de que la domesticidad estuvo sometida históricamente a una dialéctica interna que le haría transformarse constantemente hasta adaptarse a todo tipo de situaciones. Esa constante transformación y adaptación es lo que me lleva a plantear la domesticidad como una constante histórica, que podemos rastrear en otras sociedades y en otras civilizaciones con las lógicas diferencias que caracterizan a los diversos contextos históricos y culturales. De ahí la necesidad de realizar un recorrido por las diferentes culturas que florecieron paulatinamente en el curso de la humanidad para observar la domesticidad como un hecho social, uno de esos principios socioculturales básicos alrededor del cual se acabaría articulando la familia y la sociedad.

La escenografía y el imaginario creado alrededor de la domesticidad puede proporcionar mucha información sobre los valores de una sociedad determinada, sobre los 
grupos sociales que la conforman y sobre las normas y reglas que dictaban las buenas conductas y el buen hacer. Pero no solo eso. También facilita muchos datos sobre la realidad vivida, sobre las distintas vivencias y experiencias cotidianas que siguen, en numerosas ocasiones, una dinámica propia, al margen o no siempre en consonancia con la regulación oficial. De esta manera estaremos en condiciones de captar la profunda disociación existente entre la normativa imperante y la realidad de la existencia; de calibrar el pulso entre la imagen de una sociedad profundamente normatizada y unas personas que viven la rutina diaria en una sociedad que discurre por cauces ajenos a la norma. Todo un sistema de vida que tiene su reflejo, de forma inevitable, en la configuración del orden doméstico. La domesticidad se rige, como todos los actos de la vida cotidiana, por la rutina, por la aplicación de unas reglas estereotipadas, por la asunción de unos rituales perfectamente delimitados por la ideología dominante; pero su propio dinamismo le hace proclive a rupturas, a interrupciones, a soportar cambios y revestir múltiples formas, tanto de aceptación como de rechazo.

De hecho, no es muy conveniente hablar de domesticidad en singular, ya que cada grupo social, cada situación histórica, cada sistema de pensamiento, y cada cultura tienen una forma particular de entenderla, de vivirla y de expresarla. Precisamente a causa de esa pluralidad, la domesticidad concreta que me propongo analizar es la domesticidad burguesa, que será sometida a un proceso de construcción a lo largo de los siglos modernos para dar cabida a la formación de la familia-tipo de la sociedad liberal. Para hacerla posible fue necesario reexaminar, a la luz de los nuevos presupuestos que demandaba la burguesía, los principios morales, religiosos e ideológicos donde habría de sustentarse para legitimar el nuevo modelo a seguir. Un tipo de unidad familiar que responde a una tipología concreta, en consonancia a una estructura social y económica en la que cada miembro de la familia, convertido en sujeto individualizado será adjudicatario de unos cometidos concretos según los dictados del capitalismo y de la nueva sociedad liberal.

La escala primaria de análisis requiere formular los conceptos, metodologías y criterios para proceder al análisis temporal y espacial del ámbito doméstico; es preciso construir un armazón teórico y conceptual, lleno de interrogantes donde aplicar métodos y categorías analíticas fundamentados con un sólido y riguroso aparato documental que pueda desembocar en resultados concluyentes. Esto nos conduce a plantear algunas cuestiones de partida para poder situar las coordenadas espacio-temporales del trabajo y el objeto de análisis. Primera cuestión: ¿qué fue antes el marco espacial donde se fue aplicando progresivamente un concepto que con el tiempo mostraría un estilo de vivir o la forma de vida que acabaría conformando un espacio donde se desarrollaría lo que ha venido en denominarse ámbito doméstico? Las posibles respuestas a esa interpelación me llevaron a un segundo interrogante: cuándo, en qué momento histórico concreto surge la domesticidad; ¿podemos entenderla de la misma manera en los distintos contextos sociales? evidentemente no, por lo que quizás fuera útil comenzar haciendo una tipología de ella. No tiene la misma significación social ni histórica la domesticidad que se observa en la Roma clásica de la que adoptará la burguesía puritana en la Europa del siglo XVII, por poner un ejemplo. Estas reflexiones me llevaron a la tercera pregunta, 
quién fue el sujeto (histórico) activo capaz de ordenar o construir ese espacio y, de modo inevitable, a las derivadas de ellas: sobre qué pilares se apoyó para hacerlo, con qué medios contó para ello y qué consecuencias tuvo en términos micro y macrosocial.

La domesticidad es una forma de entender las prácticas de vida con las lógicas consecuencias que diferencian a unas sociedades de otras. No hay que olvidar que es un elemento constante en todas las sociedades, marcado por la continuidad, que se ha ido perpetuando y redefiniendo regularmente, por lo que la nueva pregunta que cabe hacerse es dónde pudo desarrollarse primero, ¿en la sociedad rural o en la cambiante sociedad urbana donde, además, se forja la burguesía moderna?. No hay duda de que cada época tiene su propio concepto de la domesticidad y la desarrolla de forma distinta, adaptándose a sus circunstancias socio-históricas. Como decía al principio, este estudio debe ser, necesariamente, interdisciplinar, por lo que hay que recurrir a distintas perspectivas, sobre todo desde el punto de vista conceptual y metodológico de aquellas disciplinas afines que contribuyan a lograr obtener una idea más global y completa. $\mathrm{Si}$, por un lado es fundamental tener en cuenta la base económico-social donde se sustenta la domesticidad, entonces habrá que recurrir a la Historia Social, y a la contribución de la Historia Económica, de la Historia del Derecho y de la Sociología. Si hemos de centrar nuestra atención en la dimensión espacial donde se aplica y desarrolla la domesticidad, habrá que recabar el auxilio de la Historia de la familia, de la Historia de la Arquitectura y del Arte, y de la Cultura material. Para el estudio de los discursos y de las representaciones nos serviremos de la Historia Cultural. Otra de las piedras angulares para abordar su estudio es aplicar la perspectiva de género, lo que significa que hay que acudir inexcusablemente a las aportaciones realizadas por la Historia de las Mujeres para entender la realidad doméstica ya que son ellas las que terminaron dando su impronta a ese espacio, acabando incluso por ser identificadas con él. Todo ello enmarcado en lo que hoy se entiende dentro de la Historia de la vida diaria, como el hecho cotidiano, según se ha señalado anteriormente.

En cuanto a los fondos documentales ${ }^{10}$, la documentación notarial es básica para entender la configuración interna de los hogares. Registrada en diferentes protocolos como testamentos, inventarios de bienes, escrituras de dote, contratos de compra-venta, o donaciones, permite contemplar la cultura material en toda su gama de objetos de uso (menaje del hogar) y de ostentación; entre ellos cabe citar desde los artefactos referidos a la iluminación, calefacción, cocina, aseo e higiene, vestimenta, hasta el incipiente mobiliario de todo tipo donde puede seguirse, también, el progreso técnico y tecnológico de las diferentes sociedades. Las fuentes literarias en todos sus géneros, desde la tratadística moral y religiosa, la literatura de la civilidad, los manuales de confesores, la literatura de creación -la comedia, el drama y la novela recrean y aportan numerosas pistas sobre los interiores domésticos- serán de gran ayuda. Los tratados de arquitectura y las normativas legales en relación a las viviendas son también un

10. Este punto acabo de desarrollarlo con más amplitud en mi trabajo «La historia de la vida cotidiana en la historiografía modernista. Algunas reflexiones», en FRANCO RUBIO, Gloria A. (ed.): La vida de cada día. Rituales, costumbres y rutinas cotidianas en la España Moderna. Madrid. Al-Mudayna, 2011, pp. 17-65. 
camino interesante a desbrozar. La correspondencia, el género epistolar y los diarios conforman un importante banco de datos muy interesantes donde prima el tratamiento de aspectos referidos a lo personal, la privacidad y la intimidad. Asimismo pueden contribuir los libros y notas de contabilidad doméstica. Las fuentes iconográficas son otro filón al que hay que interpelar, sobre todo cuando son analizadas como fuente de conocimiento histórico acerca de las bases materiales de una sociedad, así como de las costumbres y hábitos que tiene; desde la constatación de una realidad reflejada en la composición de las obras, o como marco difusor de modelos ${ }^{11}$. La pintura holandesa del siglo XVII es paradigmática en cuanto a la captación de esos interiores de la burguesía a que voy a referirme.

Intentar responder a los interrogantes enumerados anteriormente, y a otros que puedan surgir en el marco de la investigación, me ha conducido a delimitar en una estructura triple el contenido del trabajo:

1- La domesticidad entendida como teoría y como práctica, como idea y como experiencia. A nivel teórico la encontraremos formulada por pensadores, ideólogos e intelectuales, pertenecientes tanto a la institución eclesiástica como al mundo laico. Expresada a través de la cultura oral, visual y escrita, será presentada al conjunto de la sociedad como modelo ideal y difundida a través de una gama variada de medios propagandísticos, que van desde el sermón religioso a todo tipo de textos. Es preciso indagar en los escritos de los canonistas, moralistas, confesores, escritores, filósofos y políticos para analizar su impacto en la vida corriente y calibrar su adaptación progresiva a las formas de vida de la gente. Esto supone hacer un análisis crítico de los discursos modeladores de conductas que fijaban el canon ideal de vida.

A nivel práctico puede ser entendida como experiencia y vivencia, pero también como actitud o cualidad en la forma de entender y vivir la vida y algunos aspectos de ella de una manera determinada, lo que nos lleva a tener en cuenta la significación asimétrica que tiene la domesticidad en hombres y mujeres, adultos, niños y ancianos, sus diferentes formas de asumirla, su predisposición o rechazo a ella, llegando a ser codificada como estilo de vida.

2- Lo doméstico. Remite a una vertiente espacial donde se ejerce y se desarrolla la domesticación de los individuos a tenor de la domesticidad. Representa una estructura social básica, y como tal debe ser estudiada. Es aquélla que expresa la forma en que los actores sociales nacen, viven se reproducen y mueren. Es un campo de estudio que, a pesar de haberse ido ampliando, diversificando, enriqueciendo y renovando paulatinamente, sigue estando sometido a grandes desafíos de tipo teórico, metodológico y empírico porque se trata de un espacio polivalente donde se superponen distintos planos que corresponden a la economía, a la supervivencia, a la sociabilidad, a la cultura, a manifestaciones de la religiosidad etc. Al coincidir con el terreno más privado e íntimo

11. BuRKE, Peter: «Cómo interrogar los testimonios visuales», en PALOS, Joan L. y CARRIÓ, Diana (ed.): La historia imaginada. Construcciones visuales en la Edad Moderna. Madrid. CEEH, 2008, pp. 29-40. FERnÁNDEZ VALENCIA, Antonia: «Pintura, protagonismo femenino e historia de las mujeres». Arte, Individuo y Sociedad. 9, 1997, pp. 129-157. 
de las personas, tiende a confundirse con la privacidad y lo privado, lo que puede inducirnos a error puesto que son dos fenómenos distintos, con sus propias particularidades, independientemente de que en su proceso haya muchos puntos de coincidencia, como luego veremos.

Según M. Foucault «podría escribirse toda una historia de los espacios que sería, al mismo tiempo, una historia de los poderes, que comprendería desde las grandes estrategias de la geopolítica hasta las pequeñas tácticas de habitat, de la arquitectura institucional, de la sala de clase o de la organización hospitalaria, pasando por las implantaciones económico-políticas» ${ }^{12}$.

3- La domesticación. Es decir, el proceso histórico a través del cual se ha conformado la personalidad de los individuos mediante la asunción de los principios teóricos de la domesticidad y su ejercicio práctico en un espacio concreto que se ha denominado doméstico. La domesticación entendida como proceso supuso la adjudicación al ámbito doméstico de una función reglada de amaestramiento, amansamiento y disciplinamiento de los individuos, lo que andando el tiempo vendría a constituir el primer nivel de lo que será la civilidad.

De hecho, la domesticación ha discurrido de forma paralela, por un lado, con el progreso del individualismo como teoría general de la vida social. Por otro, con el proceso de civilización, estudiado magistralmente por Norbert Elías ${ }^{13}$, por su capacidad para domeñar los impulsos primarios del individuo ya que la civilidad contribuyó a la doma (domesticación) de los instintos, sensaciones y sentimientos, favoreciendo el auto-control. Fue asumido por la burguesía como forma de vida, a modo de seña de identidad. Como fenómeno se benefició del triunfo de la privatización que corre parejo a éste y como proceso se fue desarrollando durante la edad moderna hasta alcanzar su triunfo con el liberalismo.

La domesticidad se reinventa o se redefine en la época moderna en el interior de los hogares burgueses gracias a una nueva forma de entender la vida, la familia y las relaciones entre sus miembros; en suma, gracias a la ideología liberal-burguesa que hace de la familia conyugal el espejo del orden social, el microcosmos perfecto para la consecución de un nuevo orden social burgués. Convertida en una de las formas culturales más difundidas por la retórica discursiva oficial -especialmente por parte de moralistas y eclesiásticos, sin olvidar a escritores y políticos especialmente a finales del Antiguo Régimen- supo introducirse por los intersticios del dispositivo social hasta acabar configurando un escenario específico, marcado por una identidad propia que le diferenciaría de otros espacios, contribuyendo a la formación del espacio social que se iría imponiendo en el siglo XVIII, de un lado la esfera privada (de la que acabaría formando parte) y de otro la pública.

12. FouCAUlt, Michel y otros: Espacios de poder. Madrid, La Piqueta, 1981.

13. ELÍAS, Norbert: El proceso de civilización. Investigaciones sociogenéticas y psicogenéticas. México. FCE, 1989. 
Impulsada en la modernidad por la burguesía, fue asumida por el conjunto de la sociedad, estando presente en todos los grupos sociales, desde los que se encontraban en los sectores más elevados hasta los que se hallaban en escalones inferiores, aunque en grados de aceptación distintos. Sirvió de instrumento y manifestación a numerosas actividades y experiencias cotidianas hasta convertirse en un paradigma cultural que acabaría identificando a los hogares burgueses. De ahí la afirmación de que este proceso está ligado a la burguesía como sujeto histórico y motor del mismo que supo llevar a cabo con el liberalismo como ideario.

Aunque dicho proceso se estuvo realizando durante toda la Edad Moderna, fue a finales de la centuria ilustrada, con la emergencia de la burguesía como clase dominante, en el momento en que el espacio social fue dividido en dos esferas opuestas, la pública y la privada/doméstica, cuando hay que situar el momento clave en que fue impuesta como modelo hegemónico de organización social. Es en este proceso de redefinición del espacio social donde hay que incluir el proceso de domesticación del individuo y la construcción del ámbito doméstico. Y así como se ha concedido tradicionalmente especial atención a la esfera pública, debemos proceder a estudiar la doméstica para distinguirla de la privada.

Hay que tener presente que en los discursos de la domesticidad se superponen estratos culturales distintos, unos cultos y otros populares, unos civiles y otros eclesiásticos. La novedad del momento a que me estoy refiriendo es que serán los ambientes laicos y cultos -en este sentido comparto la tesis de Stone ${ }^{14}$ - los más comprometidos con este discurso ya que la domesticidad fue elaborada para la formación de una familia determinada, la burguesa. No es casualidad que en las fuentes iconográficas veamos plasmados estos dos conceptos de la domesticidad, y sus grandes diferencias; ante el avance en la sociedad europea de una nueva concepción de la domesticidad, en torno a la familia nuclear, tenemos dos versiones antagónicas, según se trate de la Europa católica y la reformada. Mientras en la zona europea partidaria del primer credo el modelo ideal de familia aparece ligada a la tradición bíblica o a la genealogía clásica configurada según la Sagrada Familia, en el mundo reformado veremos una intensa producción pictórica donde la propia familia burguesa, formada por padres y madres con sus hijos alcanza una determinada configuración, que será fijada en el retrato como modelo idealizado de ese estilo de vida.

Aunque la noción de domesticidad había estado presente en todas las culturas a lo largo de la historia, fue la burguesía quien se encargó de hacer de ella un estilo de vida que fue difundido por todas partes hasta imponerlo como forma de convivencia perfecta a finales del Antiguo Régimen; para el hombre burgués el entorno doméstico significaba el refugio donde poder encontrar el descanso apropiado tras la actividad ejercida en el exterior que le demandaba su trabajo; en el caso de las mujeres el hogar así concebido sería expuesto como el espacio natural donde desarrollar y pasar su vida;

14. Stone, Lawrence: Familia, Sexo y Matrimonio en Inglaterra: 1500-1800. México, Fondo de Cultura Económica, 1990 (la edición inglesa es de 1977). 
alcanzar la domesticidad implicaría para ellas centrar sus esfuerzos en lograr el paraíso perfecto para su marido, además de atender a los hijos, administrar y cuidar de la casa, y controlar a la servidumbre. Que fuera la burguesía la que acabara imponiendo una domesticidad determinada no significa que en el resto de los grupos que conformaban la sociedad no se diera otro tipo de domesticidad. Evidentemente, en las familias complejas, muchas de ellas radicadas en zonas rurales y circunscritas a círculos campesinos también existía un orden doméstico; solo que estaba regido por reglas muy distintas a las que venimos observando en las familias burguesas.

La recuperación del mundo clásico gracias al Renacimiento permitió rescatar la terminología que se había utilizado en tiempos del imperio romano para denominar al cuerpo colectivo de ciudadanos con la forma adjetival de publicus y a lugares como calles, espacios y foros con la sustantiva de publicum. La formación del estado y el empuje del absolutismo contribuyeron a diluir dicha imprecisión al ir adjudicando cada actividad humana a un recinto concreto hasta el punto de que, poco a poco, se fue fijando en el imaginario colectivo la asociación de lo público con el estado y sus organismos. En el siglo XVIII al sustantivo público se añade una nueva acepción que ya no está unida a la autoridad del estado sino separada de éste, designando la opinión de los particulares y su audiencia, así como su capacidad de reproducción. Es entonces cuando se empieza a hablar de que el espacio social está subdividido, a su vez, por otros dos grandes espacios, el público, frente al privado y doméstico y, entre medias, de contornos todavía un tanto imprecisos, el semi-privado o semi-público. Uno de los efectos más significativos de esa re-definición se encuentra en el establecimiento de una jerarquía entre ambos, posteriormente legitimada a nivel social, quedando la esfera privada y doméstica en una posición secundaria ante la primacía social de la pública. Por eso, la ubicación de la mujer en el ámbito doméstico, un espacio socialmente devaluado, la (re)colocó en una posición social -y legal- de inferioridad y subordinación respecto al hombre, imagen que ya fue teorizada con claridad meridiana por el filósofo John Locke en su Segundo tratado sobre el gobierno civil (1690), donde escribía «aún siendo capaz de reconocimientos dispares, cada sujeto encuentra su identidad en su espacio: el hombre como semejante dentro de una sociedad plural, mientras que la mujer hallará en la naturaleza una pertenencia que justificará su incapacidad para incorporarse a la esfera pública» ${ }^{15}$; una idea que un siglo después llevaría Rousseau a su culminación al presentar una rígida segregación de los espacios y funciones de cada $\operatorname{sexo}^{16}$.

Espacio doméstico y espacio exterior acabarán siendo a finales del Antiguo Régimen, términos y ámbitos excluyentes aunque durante buena parte del periodo hubo una intensa permeabilidad entre ambos, además de una constante interferencia que a veces ha sido difícil de determinar. Gracias al proceso de privatización desarro-

15. LOCKE, John: Segundo Tratado sobre el gobierno civil. Madrid. Alianza, 1990.

16. Al respecto Ángeles Jiménez Perona dice que «no es que primero se defina lo político y luego se excluya a las mujeres, sino que lo político queda definido en un solo movimiento al excluir a las mujeres», vid. JimÉneZ Perona, Ángeles: «La construcción del concepto de ciudadanía en la modernidad». Arenal. 1995. Vol. 2, nº 1, pp. 25-40. 
llado en los siglos modernos, el término privado, más restrictivo que el doméstico al estar implícito en éste, iría superponiéndose a aquél de manera que, en el siglo XVIII, en el momento de reformulación del espacio social en términos políticos encontraremos claramente constituidas las dos esferas que conocemos en la actualidad, la privada, muchas veces identificada con lo doméstico - de forma errónea a mi entender- y la pública.

Desde que autores como Habermas, Koselleck, Roche, Chartier, Starobinski, Ferrone, Gordon, Landes, Ozouf, Baker, Goodman, Gunn, Van Horn y tantos otros insistieron en estudiar el nacimiento de la esfera pública, y la formulación del espacio social, hasta ahora único, en privado y público, ha habido una intensa producción historiográfica que básicamente se ha centrado en analizar la construcción del segundo ${ }^{17}$. En cambio, esa otra parte del espacio social que acaba siendo definido por oposición al primero quedó más difuso, abstracto e indeterminado. Según algunos autores lo doméstico es privado por definición. Se ha afirmado que lo que no era público era privado y dentro de ese «cajón de sastre» que alude a lo privado aparecía lo doméstico, a menudo identificado con él. Es decir que, de forma genérica el ámbito doméstico aparecía subsumido en lo privado con el agravante, además, de que en ausencia de una definición concreta sobre ambos términos se aplicaran de forma indiferente lo que agregaba mayor confusión. Llegados a este punto es necesario actuar con cautela porque lo doméstico no solo es privado sino que es viable hablar de su dimensión pública, al existir una sociabilidad doméstica proyectada al exterior y marcada por la publicidad como sucede con los salones, tertulias, gabinetes de lectura y Sociedades Patrióticas de finales del Antiguo Régimen.

Por tanto, es conveniente estudiar de forma conjunta y en paralelo los dos procesos, tanto el de privatización como el de publicidad, dada su complementariedad. La construcción del espacio público tiene su verdadero contrapunto en la construcción del ámbito doméstico. Cuanto más perfilemos los límites de uno y otro y de ambos entre sí, más fácil será obtener una definición satisfactoria sobre ese espacio social que en el siglo XVIII permite ir avanzando en una evolución distinta, como líneas divergentes que no se pueden separar, la delimitación de un campo presupone la del otro. Ello a pesar de que, aparentemente, el liberalismo concedió mayor importancia a la formulación del espacio público, dada su estrecha conexión con la creación del mercado.

\section{PROPUESTAS Y POSIBLES VÍAS DE INVESTIGACIÓN}

A comienzos de la modernidad, en uno de los tratados de arquitectura más relevantes, obra de León Baptista Alberti, se observa con una cierta claridad el concepto de lo que la época empezaba a entender por domesticidad, ya que aparece una idea de distribución de las actividades y de segregación de los objetos, en función de la experiencia del vivir:

17. Remito a la ingente bibliografía existente. 
«Al principio el género de los hombres buscó para sí algunos espacios de sosegar en alguna región segura, y hallada área o planta cómoda y agradable para su necesidad asentó allí, y ocupó aquel sitio de suerte que no quiso que en un mismo lugar se hiciesen todas las cosas domésticas y particulares, sino acostarse en una parte, y en otra tener el hogar, y en otra poner las demás cosas para el uso» ${ }^{18}$.

En su caso se trataba de un arquitecto, no un moralista, aun cuando serán éstos los que buscarán dotar a ese ámbito de las reglas necesarias para la ubicación social de los individuos y la asignación de sus tareas según lo que Carol Pateman ha denominado «contrato sexual» ${ }^{19}$.

A partir de estas consideraciones mi hipótesis se basa en las dos premisas siguientes: 1- gracias al individualismo -una de las características más emblemáticas de la ideología burguesa- la burguesía, operando como sujeto histórico, pudo transformar las antiguas estructuras familiares complejas, que pasaron de ser (entre otras cosas) una unidad de producción en el plano económico a una institución social basada en la conyugalidad como eje del nuevo modelo familiar. Una de las principales consecuencias de la pérdida de la función económica de la familia está estrechamente relacionada con la habitabilidad; es decir, con el marco espacial donde se habitaba, mezcla de trabajo y de las vivencias cotidianas, como expresión de una nueva manera de concebir los modos de vida y el lugar donde se desarrolla, el hogar. 2- La nueva domesticidad exigió un replanteamiento de las funciones de los miembros de la familia, lo que exigió una remodelación de las identidades genéricas en función de los estereotipos vigentes de la masculinidad y la feminidad; en adelante el padre-marido será el encargado de abastecer a la familia, realizando sus actividades laborales fuera del hogar mientras que a la mujer-esposa, alejada de las tareas productivas, se le asignará el espacio del hogar donde deberá encargarse de dar satisfacción a las necesidades afectivas, de ahí su importante papel de esposa y madre. Esto explica el resurgimiento con fuerza del modelo de mujer doméstica confinada en la vivienda conyugal, en oposición al modelo mundano que había hecho posible la presencia femenina en la sociedad galante ilustrada. Un arquetipo femenino que, cuando triunfe la sociedad liberal burguesa, será considerada el ángel del hogar.

Para la verificación de esa hipótesis - que tuve la ocasión de presentar públicamente en un Seminario celebrado en Córdoba en $2010^{20}$ - me dispongo a explicar el proceso de domesticación a partir de una serie de factores a los que voy a llamar «indicios» tomando prestado a Philippe Aries el esquema que aplicó en su «Introducción»a la Historia de la Vida privada para indicar cómo fue llevado a cabo históricamente el proceso de privatización. El autor citado atribuía las grandes modificaciones operadas

18. Alberti, Leon Baptista: Los diez libros de Architectura. Madrid. Imprenta de Alonso Gómez. 1582, libro I, p. 6.

19. Pateman, Carol: El contrato sexual. Barcelona. Anthropos, 1995.

20. Franco Rubio, Gloria A.: «El ámbito doméstico y la construcción de la domesticidad». Ponencia presentada en el Coloquio Internacional «Conflictos y rutinas. Lo cotidiano en el mundo hispánico». Organizado por la Universidad de Córdoba. 15-17 de noviembre de 2010. 
en el terreno de las mentalidades y, en particular, a la idea que las personas tienen de sí mismas y de su papel en la vida diaria a tres acontecimientos externos pertenecientes a la historia político-cultural: 1- el nuevo cometido del estado, 2- el desarrollo de la alfabetización y la difusión de la lectura y 3- las nuevas formas de religiosidad que se establecen en los siglos XVI y XVII. A continuación, desarrollaba con minuciosidad los diversos itinerarios a través de los cuales dichos acontecimientos pudieron penetrar en la vida cotidiana de la gente: la literatura de civilidad que inculcaba actitudes nuevas respecto al cuerpo; el conocimiento de uno mismo a través de la escritura íntima o autógrafa -diarios, correspondencia; la búsqueda de la soledad por placer; el ejercicio de la amistad personal basada en afinidades y sentimientos, por encima de otros intereses -familiares, profesionales, clientelares; la valoración del gusto como manera de presentación de uno mismo y de los bienes que posee, y la comodidad, resultado del acondicionamiento del ámbito de la vida privada a las necesidades del yo individual. Indicios que irán quedando fijados socialmente, a partir de la reformulación y nueva definición que se hizo por parte de los teólogos católicos y pastores protestantes así como de los intelectuales laicos ${ }^{21}$.

Por mi parte, en lo que se refiere a la domesticación de los individuos, un proceso que vendrá marcado por numerosas coincidencias con el de la privatización, vamos también a examinar los indicios de esa nueva forma de entender la vida, que impregna las mentalidades, las ideas y las vivencias, permeabilizando las distintas dimensiones de la vida, hasta acabar por fijar las bases reguladoras de las conductas y de los modelos considerados como ideales en el nuevo orden social: 1- el empuje del individualismo; 2- la dialéctica entre lo doméstico y lo laboral en el interior de las viviendas; 3- los cambios en la estructura familiar que permite la aparición de la familia nuclear y el desarrollo de la conyugalidad; 4- la asignación del espacio doméstico a las mujeres, que traería consigo dos importantes consecuencias, la feminización de la casa y la consolidación del modelo de mujer doméstica; 5- el auge de la privacidad y el triunfo de la intimidad, y 6- las transformaciones operadas en el interior de las viviendas, que redundan en la especialización de las dependencias domésticas y en el nacimiento de lo que después sería considerado como hogar. Aunque finalmente la domesticación alcanzaría a todos los grupos sociales, la percepción de esos indicios es susceptible de ser observada con mayor facilidad en las formas de vida que iría adoptando la emergente burguesía urbana, como trataré de demostrar en los resultados que pueda ir obteniendo -y ofreciendo- conforme vaya avanzando en la investigación.

21. ARIES, Philippe: «Para una historia de la vida privada», en ARIES, Philippe y DUBY, Georges (dir.), Historia de la vida privada. Tomo 3 Del Renacimiento a la Ilustración. Madrid. Taurus, 1989, pp. 7-19. 